\title{
Role and impact of social relationships and networks in a software project team environment - a conceptual framework
}

Awie Leonard, Dawie van Zyl

Department of Informatics, University of Pretoria, South Africa

\begin{abstract}
The establishment of social relationships between information technology (IT) project team members is a phenomenon all IT professionals are exposed to and, in many cases, involved in. Furthermore, these relationships are used by IT project team members for personal as well as professional purposes. The question is what positive or negative contributions do these kinds of relationships have on the project itself? Past studies have placed little focus on these social relationships and networks, and have failed to take cognisance of their importance in the IT project environment. This paper demonstrates that social relationships and networks in the IT project environment play a significant role in project teams and should be managed in such a way that the team members and the project as a whole can benefit from them. A partial grounded theory (GT) research approach was followed. Interpretive patterns from GT enabled inferences to be drawn about the role and impact of social relationships and networks in IT project teams. The research findings provide practical considerations and highlight potential problem areas. A conceptual framework is proposed to support management in decision making and to give them a better understanding of the complexities involved in such relationships.
\end{abstract}

Keywords: Projects, social relationships, social networks, communication, grounded theory.

\section{Background and problem description}

The information technology (IT) project management literature is extensive with regard to success factors as well as the causes of failure; however, little focus is placed on the role or importance of social relationships and networks within IT projects.

Liebowitz (1999) holds that the greatest threat to the success of any IT project is the failure to communicate. This statement draws attention to the area of the research problem. Although one wants to see a project environment where a culture of sound communications is promoted, it is difficult for any project manager to 'control' any influence this might have on team members and, as such, on the progress of a given project. Sauer (1993) believes that a major part of the problem of IT project failure is the lack of recognition that information systems development is largely a social and political process. This view is also shared by Standing (1998). Considerable effort has already been spent on the process of managing IT projects and has produced multiple methodologies and methods for project management and the IT software development life cycle (Standing \& Bavington, 1996). 
Ashworth \& Carley (2006) state, for example, that:

Social network theories suggest that the types and degrees of an individual's relationships in social and communication networks are key impactors of group performance, while resource dependency theory suggests that non-social factors, such as knowledge and skills, figure at least as prominently as social dimensions in determining such performance.

Social factors are increasingly being considered as important for achieving more consistent and sustainable success in corporate environments. Organisations are spending increasing amounts on social responsibilities outside their operating environments, as their customers are taking cognisance of these issues and are demanding these efforts. Inside the organisations, similar efforts are being made to heed the social factors, especially from a human resources point of view.

In organisational theory, managers are viewed as contributing the value of their social networks, over and above the skills they have acquired through experience and education. These values or assets refer to the social capital of the manager. Scholars have highlighted the ability of these social networks that can be used to the individual's or organisation's advantage (Gargiulo \& Benassi 2000; Ashworth \& Carley 2006). With this in mind, the question is how social relationships and networks within IT project teams are viewed, instead of focusing only on those of the project managers. The social capital of the individuals participating in IT project teams is an influencing factor on the social networks that are active within the project teams.

The first consideration is that of determining the strength of these social networks. Network strength can be defined as the frequency of communication, while the degree of the network is defined as the number of direct links with other network members (Monge \& Contractor 2003, cited in Hovorka \& Larsen 2006).

Social networks have a key function in the social information processing within an organisation, especially relating to connecting social influence, knowledge and the organisational culture to the actual projects at hand. This influence is depicted in figure 1.

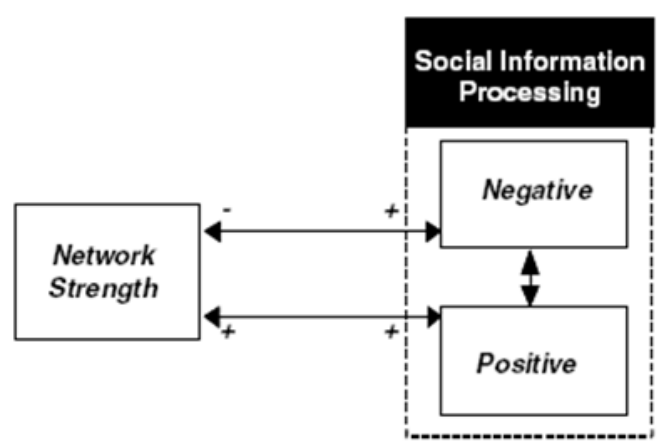

Figure 1. Interaction of network strength and social information processing (Hovorka \& Larsen 2006)

In summary, the problem under investigation in this research was to determine the role and nature of social relationships and networks within and between the IT project teams, as well as their influence in the success or failure of such projects. 
In the rest of the paper a description is given of how the research was done and how data was gathered. The paper gives a theoretical overview of social relationships and networks. After this, data is presented and discussed to illustrate how relationships work in practice and how they impact or influence project teams and project outcomes.

\section{Theoretical background on social relationships and networks}

The establishment and maintenance of sound relationships

Relationships between end users and team members of IT projects are described by Leonard (2002) as intriguing and complex. According to Leonard, a large number of elements (support, cooperation, knowledge and commitment, among others) are involved during the establishment and maintenance of sound relationships. Furthermore, he argues that if any of these elements are disturbed, the whole relationship is disturbed. In other words, these elements form a holistic 'unit'. Each of these elements, therefore, plays a specific social role in a relationship, which impacts on the soundness of a relationship and on the cooperation between team members.

In order to overcome the problem of poor relationships between IT professionals and end users, for example, it is argued that a 'human-behaviour' strategy of some kind should be followed. This strategy should involve, among other things, focusing on those social issues that will enhance trust, commitment and cooperation. Reich \& Benbasit (1999, cited in Leonard 2002) point out that there are two dimensions to strategy creation: the intellectual dimension and the social dimension. The social dimension was the focus of this research.

Sound social relationships could be regarded as an important ingredient for any working environment; not only among employees in general, but also for the purpose of organisational learning and support.

\section{The Socio-Technical-Constituencies framework}

Collinson (2000) defines the Socio-Technical-Constituencies (STC) framework (see figure 2) as a tool to map out and identify the roles of the various sources of knowledge, expertise and other factors influencing the innovation process. In particular, social, organisational, technical and economic factors are highlighted. Although Collinson's STC framework is based on the innovation process, it can be extended to IT projects that are, in essence, projects concerned with innovation. The STC framework assists in identifying the alliances, alignments and social interactions that can be critical to the success or failure of the IT project. Collinson (2000) defines socio-technical constituencies as:

Dynamic ensembles of technical constituents (tools, machines, etc.) and social constituents (people and their values, interest groups, etc.), which interact and shape each other in the course of the creation, production and diffusion (including implementation) of specific technologies.

Applying this idea to relationships and social networks allows one to emphasise the concept of interrelation and interaction between the individual team members participating in the IT project. This interaction occurs between the different sets of social constituents of the team members involved in the IT project, impacting across a variety of networks, and thus from the basis of the socio-technical constituencies. 


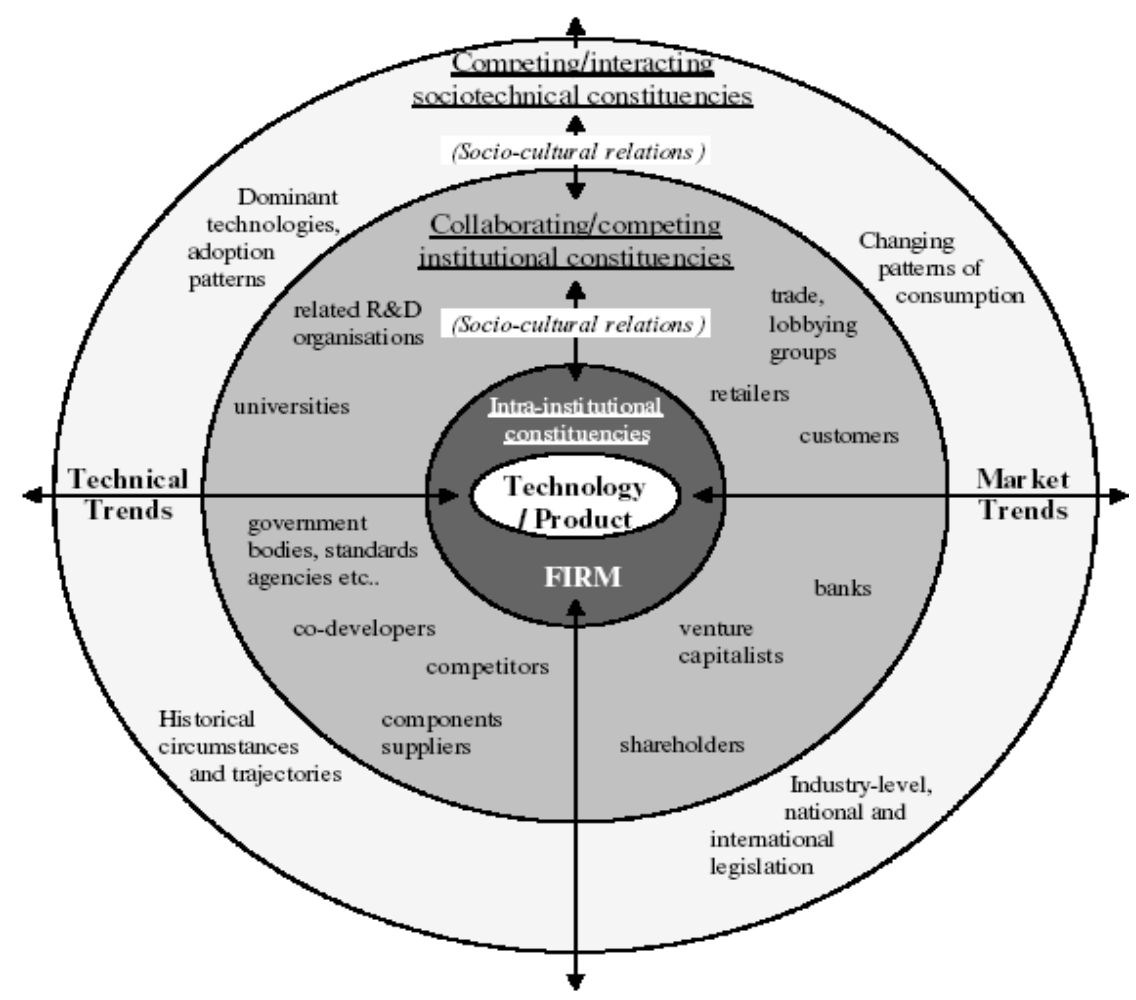

Figure 2. Socio-technical constituencies framework Source: Collinson (2000)

In IT projects, the use of the STC approach enables the identification of the social, economic and technical networks that form the basis for achieving a successful outcome. Thus the elements that can constrain or facilitate constructive social networks can be identified and addressed. The STC model thus enforces the idea that social relationships and networks are the key to the successful implementation of IT projects.

\section{Trust}

Although all the elements mentioned by Leonard (2002) are important for the establishment and maintenance of sound relationships, it is noteworthy that the element of trust could be regarded in most cases as the basic ingredient for sound relationships, and therefore more theory is given in this regard.

Trust is an important component in social relationship building, but it remains a complex and ambiguous phenomenon (Kadefors 2004). Kadefors defines trust as: ‘... a psychological state comprising the intention to accept vulnerability based upon positive expectations of the intentions or behaviour of another.' This definition implies that trust is not a behaviour, but rather a psychological state. Furthermore, Kadefors explains that trust is not a prerequisite for cooperation, but the presence of trust improves and extends the level of cooperation. 
Trust becomes important in IT projects due to the high level of cross-functional members who participate in IT projects and the associated fundamental need for cooperation.

Required trust levels are directly affected by the situational circumstances and the team dynamics within IT projects. Finding the right balance of trust is important, as there are costs associated with trust (Kadefors 2004):

- $\quad$ Direct costs are associated with the building of trust

- $\quad$ Potential costs of breaching trust

- $\quad$ Costs resulting from inefficiencies due to excessive levels of trust

Trust can be created by the following methods:

- $\quad$ Relational trust. Relational trust is created through repeated interaction between individuals. Trust is based on the personal experiences of individuals and their interpretation of events.

- $\quad$ Calculus-based trust. Calculus-based trust results when the trusting party believes that the trusted party will deliver on the promised actions, as this delivery is in the financial interests of the trusted party.

- Institution-based trust. Trust is created through institutions, such as legal systems, regulatory systems and societal systems. These systems are very much contextrelated and the levels of trust can thus differ, based on their context.

Trust is thus a context-based psychological state that is affected by the participating individuals, as well as the associated circumstances. Kadefors (2004) explains it in the following way: 'We trust a colleague or exchange partner in some situations but not in others, and decisions on whether or not to trust are continuously revised in the light of new information.'

Due to the need for cooperation in IT projects, relational trust is the prime driver of trust development in IT projects. Close cooperation, especially beneficial cooperation, is only created over time through interpersonal interactions. This implies that social characteristics and relationships developed between individuals have a direct influence on the levels of trust that exist within an IT project environment.

In the next part of the paper the empirical research is presented (based on project charter and project closure documentation) to illustrate what social activities take place in a typical IT project environment.

\section{Materials and methods}

A large South African financial bank was chosen for the investigation. The reason for using this bank was because of the large number of ongoing projects it has at any given point in time. This bank also undertakes a considerable number of IT projects on an annual basis.

Information was primarily obtained from project documentation of completed or abandoned projects within the IT departments of the corporate bank. A survey was created, based on the initial findings of the grounded theory (GT) research, and these findings were then sorted into categories. 
Based on the information analysed during the initial literature review and personal experience, the following question was formulated: Do the social relationships and networks within project teams and external to these teams influence the outcomes of such projects? During the GT process the following secondary questions were identified and addressed:

- $\quad$ How are social networks used?

- $\quad$ Do separate and distinct social networks develop within project teams?

- $\quad$ Do pre-existing social relationships and networks between potential team members influence the dynamics of a new project team?

- What factors outside the project team have an influence on the social relationships and networks?

To answer the above questions, the empirical research process took the form of reading through a large number of relevant project documentation. At the same time data was arranged, categorised and analysed. Answers to certain research questions emerged and a comparison with existing literature was done. In the following section the theoretical background is given, as well as how the empirical research process took place.

The survey used in the research is a cross-sectional survey, as it involves approaching a sample of respondents only once. The sample is regarded as a cross-section of the population under study. The survey results were used to compare subgroups (such as project managers and developers) and to evaluate relationships between variables.

The target population for the survey was limited to members (project managers, developers and other participants in IT projects) of two case studies. The survey was distributed to 100 possible candidates in the form of a self-administered internet questionnaire.

A Likert scale was used to measure the participants' views on the categories identified during the initial data collection phase. The Likert scale allows for interval scales and a full spectrum of statistical analysis. A deductive interpretive approach was applied to analyse the results of the survey.

\section{Empirical research}

The data used for the initial GT process was obtained from project documentation. These documents consisted primarily of project charter and closure documentation. The data was used to identify the concepts and categories during the data collection phase of GT. Further information relating to the concepts and categories was obtained using a survey distributed to participants from the two selected case studies, which are briefly described in the next section. 


\section{Case studies}

The two case studies used for the GT process are based on two different IT environments. The first case study relates to a primary centralised approach while the second case study relates to a decentralised federated approach. The two environments where the case studies took place are only briefly described because of space limitations.

IT environment 1 (case study 1)

In the first case a Technology Program Office was created by the bank to provide integrated end-to-end management services for the strategic project portfolio. This strategic portfolio spans multiple clusters and associated subdivisions to create a project portfolio exceeding EUR 40 million per annum. The bank makes use of program management to control the myriad projects executed concurrently within its environment. The size and volume of work requires a structured and predictable methodology to allow for the management of all stakeholders' expectations. The project management methodology used was based on the PMI PMBOK. All nine knowledge areas are implemented, but tailored to the bank's environment. Project duration varied between 9 and 18 months. Project teams are constantly changing as a large pool of resources is selected based on availability and skill set. This process is aimed at spreading the load across the available resources to minimise idle time of the full resource pool.

IT environment 2 (case study 2)

The second case focuses on the bank's Personal Loans Information Technology division, which is a full-fledged IT department that services the needs of the Personal Loans business division within the bank. The primary focus of the team is to provide and maintain information systems that cater for the specific needs of the Personal Loans mono-line. Their approach to project management was similar to that of case study 1 but were further customised in terms of the number of artefacts produced throughout the project lifecycle. The duration of projects is significantly shorter than in case study 1 , with a duration of between 3 and 9 months. The project portfolio is also smaller and more focused in terms of funding of EUR 8 million. Project teams are more stable than in case study 1 as resources are divided into project execution teams and these teams serve specific functional and IT solutions within the division. This approach is aimed at maximising resource specialist knowledge to improve the outcome of results.

\section{Analysis of data}

The ATLAS.ti software was used for the GT data ordering, data analysis and theory development phases. The initial core categories (in bold) that were identified are depicted in figure 3 below. Furthermore, the process was used to identify the impact areas as well as the impact types of social relationships and networks. 
Impact areas

The impact areas (with their related issues) of social nature are also indicated in figure 3. A brief listing of each is given below.

- The role of leadership within the project:

The presence of a strong leadership component within the project

Importance of leadership versus procedures

The level of leadership and the project outcome

The level of support for leadership within the project team.

- The project culture:

The presence of a recognisable culture within the project

The effect of the project culture on the project team

The role of the project manager in determining the project culture

The project culture versus the organisational culture

The influence of the project culture on the project outcome.

- The social relationships between team members:

The level of social relationships that develop between team members

How the social relationships are used within the project

The effect of social relationships on how team members view others.

- The individual's external social networks:

Which type of external social networks are used?

What are the external social networks used for?

- External influencing factors on the project.

The effect of external factors on the project outcome

The types of external factors influencing projects.

These impact areas were used as basis for gathering more data by means of a survey. The survey and key findings are discussed in the next section. 


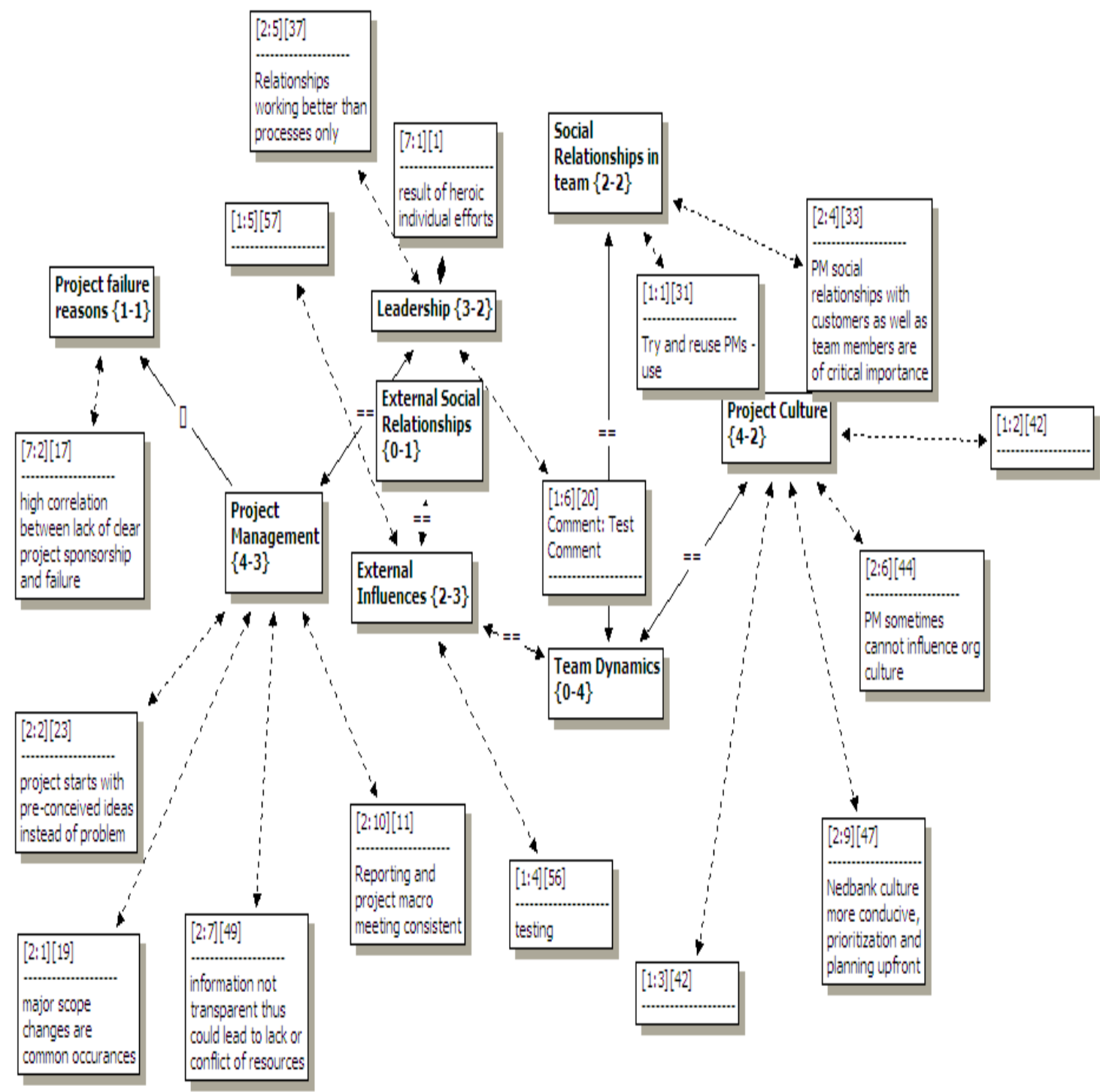

Figure 3. Network view of grounded theory data; categories, impact types and areas

Impact types

Social relationships and networks are active in information systems projects in three primary formats which are called impact types. They are as follows: influence, friendship, and advice:

Influence

Project team members establish social relationships within project team structures over time through their personal interactions. Stronger social relationships can be developed with some team members compared to others which can create areas of leverage for the individuals. These social relationships provide a platform for individuals to influence the project direction or decisions through: 
- Influencing the project leadership.

- Influencing other team members to gain support for their own ideas and agendas.

- Using their social relationships to solve problems when project structures and procedure present a stumbling block.

- Influencing the project culture.

Harnessing this influence to the advantage of the project will increase the contribution of the specific individual to be greater than just their knowledge and skills.

\section{Friendships}

Some individuals develop social relationships with other project team members to such a level that it evolves into friendships that extend beyond the project structures. These friendships can result in the creation of certain social groupings within the project team that result in the alienation of other project team members, to the disadvantage of the project. Harnessing these friendships in the composition of new project teams can result in the creation of highly effective project teams that deliver beyond the sum of the capabilities of the individuals.

Furthermore, Leonard (2002) states that these relationships have an intriguing nature. According to him they consist of two dimensions, namely a physical and abstract dimension. The physical dimension describes those elements that are necessary in order to enable contact between team members, whereas the abstract dimension describes the soft issues of a relationship. These two dimensions enable one to describe the holistic nature of such a relationship fully and to encapsulate the important elements of a supportoriented organisation, namely mutuality, belonging and connection. Because of the holistic nature of the different elements, Leonard (2002) argues that any kind of change having an effect on any of the elements of either the physical or abstract dimensions of a relationship will in fact disturb the relationship. Based on this, one can argue that social relationships and networks that are disturbed need to be managed in such a way that all role players stay focused and committed.

\section{Advice}

Individuals make use of their social networks outside the project structures to gain advice to assist them in performing their tasks and to influence the project. Individuals with strong and influential social networks can be advantageous to project teams as these networks can be used by other team members to provide validity to the project. These networks can assist greatly to identify possible external factors that could influence the project and develop associated actions to minimise potential negative impacts.

\section{Summary of survey design and results}

The survey was distributed to 100 participants across the two cases with 58 valid responses received. As stated previously, a Likert scale was used to measure the participants' views on the categories identified during the GT initial data collection phase. 
The purpose of the survey was to:

- $\quad$ Gather further information to saturate the categories identified during GT

- $\quad$ Gather personal views of participants in IT projects.

The survey illustrates clearly the huge role played by the establishment and use of social relationship and networks in a given IT project environment:

- In total, $87 \%$ of the respondents indicated that social relationships between team members developed within the project teams as well as between members of other teams. Almost two-thirds indicated that they developed stronger social relationships with some project team members than with others.

- Social relationships are used by team members within and around the structures created in the project environment.

- Project team members used their social relationships to solve problems while following project procedures as well as when the procedures proved to be a stumbling block in resolving the particular problem.

- A significant finding is that one in two respondents indicated that they made use of their social networks outside the organisation to gain knowledge so that they could influence the project. Figure 4 shows the variety of issues that could be applicable in this regard.

- A large number of participants indicated that the team members made use of their social relationships to the benefit of the project, and to their individual benefit as well.

- The project manager should heed the potential of strong social relationships with the project team members and provide leadership instead of just following and enforcing project methodology. This is also endorsed by Adams et al (2010), who state that: When project managers focus primarily on hard business tools, such as schedule, budget, and scope, they can lose sight of a more subjective aspect of the project-the team member.

\section{Grounded theory research findings}

In this section of the paper the results of the research project are discussed and illustrated. The survey results were used to deductively evaluate the importance of social relationships and networking within IT projects. The saturated network illustrated in figure 4 illustrates the role and importance of social relationships and networks in a typical IT project environment. At the end of this section a summary is given of the major findings. 


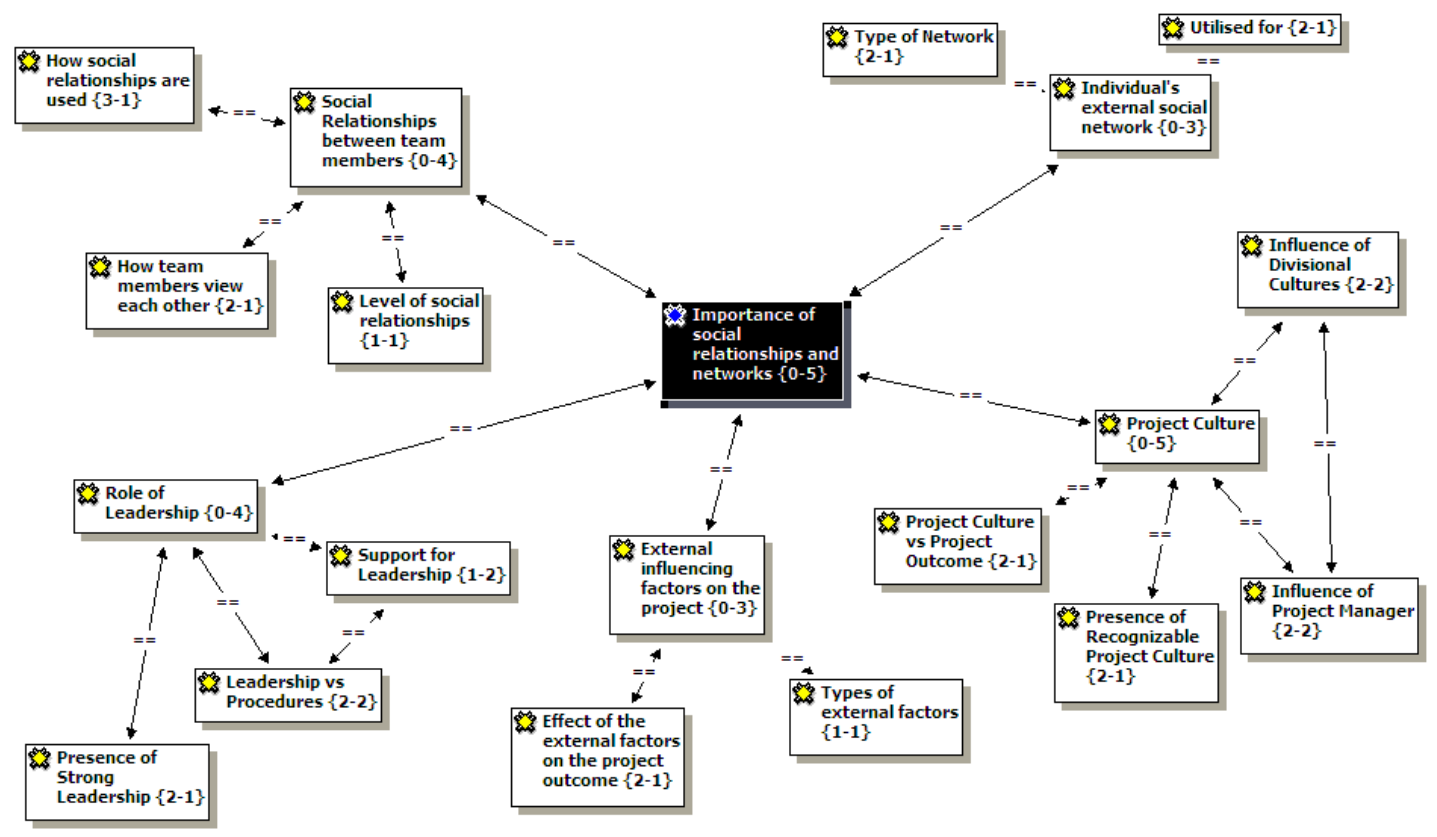

Figure 4. Saturated GT network view of how social relationships and networks impact on the different aspects of an IT project environment

\section{Summary of the major findings}

The nature of IT projects normally requires high levels of team member interaction throughout the project life cycle and thus social relationships will develop between project team members. Two-thirds of respondents indicated that they developed stronger social relationships with some team members than with others. This implies that social alignments or cliques can develop within project teams that must be monitored to prevent possible alienation of other team members. Harnessing these groupings to the advantage of the project can provide momentum and energy toward successful project delivery. Some social relationships developed between project team members to such an extent that team members developed friendships that extended beyond the project environment. Although this phenomenon is on a personal level, this could also enhance or hamper performance which needs to be monitored. 


\section{Table 1 Level of social relationships formed within the project}

$\begin{array}{llll} & \begin{array}{l}\text { I developed no } \\ \text { social }\end{array} & \begin{array}{l}\text { I developed } \\ \text { stronger social } \\ \text { relationships } \\ \text { within the } \\ \text { relationships }\end{array} & \begin{array}{l}\text { I developed } \\ \text { strong social } \\ \text { relationships }\end{array} \\ & \begin{array}{l}\text { with some team } \\ \text { members than } \\ \text { other }\end{array} & \begin{array}{l}\text { with all the team } \\ \text { members }\end{array} \\ \text { Results } & 13 \% & 65 \% & 22 \%\end{array}$

Project team members use their social relationships primarily to solve problems and to gain some level of advantage. This could be regarded as a positive development in the sense that team members will, because of certain relationships, deal with their problems as quickly as possible and enhance the team performance as a whole.

\begin{tabular}{|c|c|c|c|c|}
\hline & $\begin{array}{l}\text { Strongly } \\
\text { Agree }\end{array}$ & Agree & Disagree & $\begin{array}{l}\text { Stongly } \\
\text { Disagree }\end{array}$ \\
\hline $\begin{array}{l}\text { I used social } \\
\text { relationships to } \\
\text { overcome } \\
\text { problems (within } \\
\text { procedures) }\end{array}$ & $15 \%$ & $55 \%$ & $17 \%$ & $13 \%$ \\
\hline $\begin{array}{l}\text { I used social } \\
\text { relationships to } \\
\text { overcome } \\
\text { problems (caused } \\
\text { by procedures) }\end{array}$ & $32 \%$ & $44 \%$ & $10 \%$ & $14 \%$ \\
\hline $\begin{array}{l}\text { I used social } \\
\text { relationships to } \\
\text { gain an } \\
\text { advantage } \\
\text { (project) }\end{array}$ & $37 \%$ & $47 \%$ & $6 \%$ & $10 \%$ \\
\hline $\begin{array}{l}\text { I used social } \\
\text { relationships to } \\
\text { gain an } \\
\text { advantage } \\
\text { (individual) }\end{array}$ & $15 \%$ & $36 \%$ & $25 \%$ & $24 \%$ \\
\hline
\end{tabular}

External relationships and networks also play an important role. These social networks can be of a formal or informal nature. Formal networks include, for example, industry portals, special interest groups, former colleagues and information feeds, while informal networks include blogs, search engines and social networking tools. Individuals can also be used by other members in their social networks to influence the IT project. Influential business people can influence projects by accessing project team members directly and thus bypassing project structures. Such interventions must be monitored as it could negatively impact on the project direction or results. 


\section{Table 3 External factors}

$\begin{array}{lll} & \text { Yes } & \text { No } \\ \text { External factors had a significant influence on the project } & 52 \% & 48 \%\end{array}$

Project management methodologies and governance are central to the project structure but the project manager who provides leadership was identified as being more important than one who just enforces project methodology and procedures. The project manager does have a significant influence on establishing the project culture but needs also to be cognisant that the rest of the project team members have just as much influence and not paying attention to this aspect can create an environment where the project manager can become a peripheral figure. The project manager should be just as cognisant of the social relationships within the project team and his/her influence in these, compared with enforcing the project methodology.

\begin{tabular}{|c|c|c|c|c|}
\hline & & & & \\
\hline & Strongly & Agree & Disagree & Stongly \\
\hline $\begin{array}{l}\text { The Project manager } \\
\text { determines the project } \\
\text { culture }\end{array}$ & $9 \%$ & $41 \%$ & $36 \%$ & $14 \%$ \\
\hline $\begin{array}{l}\text { Leadership influenced } \\
\text { the project outcome }\end{array}$ & $40 \%$ & $26 \%$ & $30 \%$ & $4 \%$ \\
\hline $\begin{array}{l}\text { Leadership is more } \\
\text { important than } \\
\text { methodologies and } \\
\text { procedure }\end{array}$ & $26 \%$ & $48 \%$ & $20 \%$ & $6 \%$ \\
\hline
\end{tabular}

\section{The literature comparison phase}

The literature comparison phase in GT is aimed at comparing the emergent theory from the research with extant literature to improve the internal as well as the external validity. The most important work in this regard is that of Ashworth and Carley (2006). They conducted research using social network theory and resource dependency theory to explain the importance and performance of human capital at team levels within organisations. The focus was on the impact of social position and the knowledge of the team members on team performance. Ashworth and Carley (2006) argue that the individual's knowledge and task execution contribute more than the individual's social relationships and networks to the overall team performance. The contribution of the individual's social networks is not discounted as being unimportant; rather, it is placed lower down in the order of importance. The linkages used for social relationships and networks focused on friendship and advice within their research. This research can be viewed as complementary and additional to the literature of social network theory.

\section{Conceptual framework}

Based on the work of Leonard (2002) and Adams et al (2010), one can argue that the basis of any 'healthy' working environment for a project team would be an environment where sound social relationships prevail most of the time. In this regard, it is important to take note of the abstract elements of the definition of a sound relationship as per Leonard (2002). According to this definition, a number of soft issues play an important role during 
the establishment and maintenance of sound relationships. Based on his work, one can argue that support or a need for collaboration plays an important role in the motivation for individual team members to reach out to other team members inside the project team or external to the project team. These two elements are referred to by Leonard (2002) as a supportive culture and cooperative behaviour.

Leonard (2002) uses the following basic framework to explain the complex working environment of a project team.

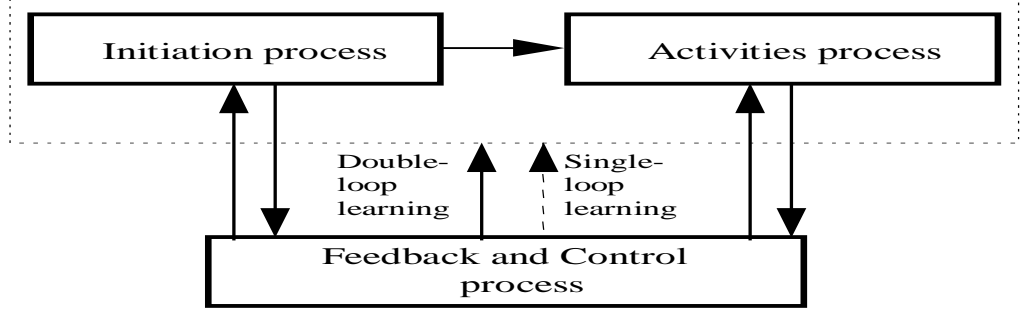

Figure 5. Saturated GT network view of how social relationships and networks impact on the different aspects of an IT project environment Source: Based on Leonard (2002)

During the initiation process, end users and the IT department (IT professionals) start working together as parties negotiating the terms and means of a specific software project. On the other hand, the activities process should be seen as the process where the rest of the project life cycle plays out. According to Leonard (2002), the nature of the activities in this process impact positively or negatively on the different elements in the physical and abstract dimensions. The feedback and control process is there to monitor this and to make the necessary changes to the project team environment.

For the purpose of this paper, the activities process in figure 5 is used as the basis to build the conceptual framework and is now explained in more detail.

The main focus of the conceptual framework is to indicate that relationship building is one of the major activities in any software project environment. Team members are initially recruited or chosen from existing IT employees. These new members normally go through an initiation or team development program. Needless to say, in most cases new members start building relationships and also bring 'external' relationship 'links' to the team. As was mentioned earlier, these external relationships could be of a positive or negative nature.

Furthermore, team members experience the need for collaboration and support as they perform their normal duties in the project team. These 'needs' can lead to the establishment of new relationships within the team or external to the team. As such, team members are influenced (positively or negatively) by other people about how to perform their duties within the project team environment. This will, of course, impact on decision making in the team and especially at the feedback and control process which normally takes place during project management 
meetings. In this regard it is also important to take note of the words of Kotlarsky \& Oshri (2005):

Collaboration is a complex, multi-dimensional process characterized by constructs such as coordination (Faraj \& Sproull, 2000), communication (Weick \& Roberts, 1993), meaning (Bechky,2003), relationships (Gabarro, 1990), trust (Meyerson et al., 1996) and structure (Adler \& Borys, 1996).

According to them the IS literature has discussed at length some factors that support successful collaboration. To put it in their own words: 'successful collaboration is the process through which a specific outcome, such as a product or desired performance, is achieved through group effort'. It follows that the forming of sound relationships inside or outside the project team for the purpose of achieving better results on project related activities should have a positive impact on individual member performance.

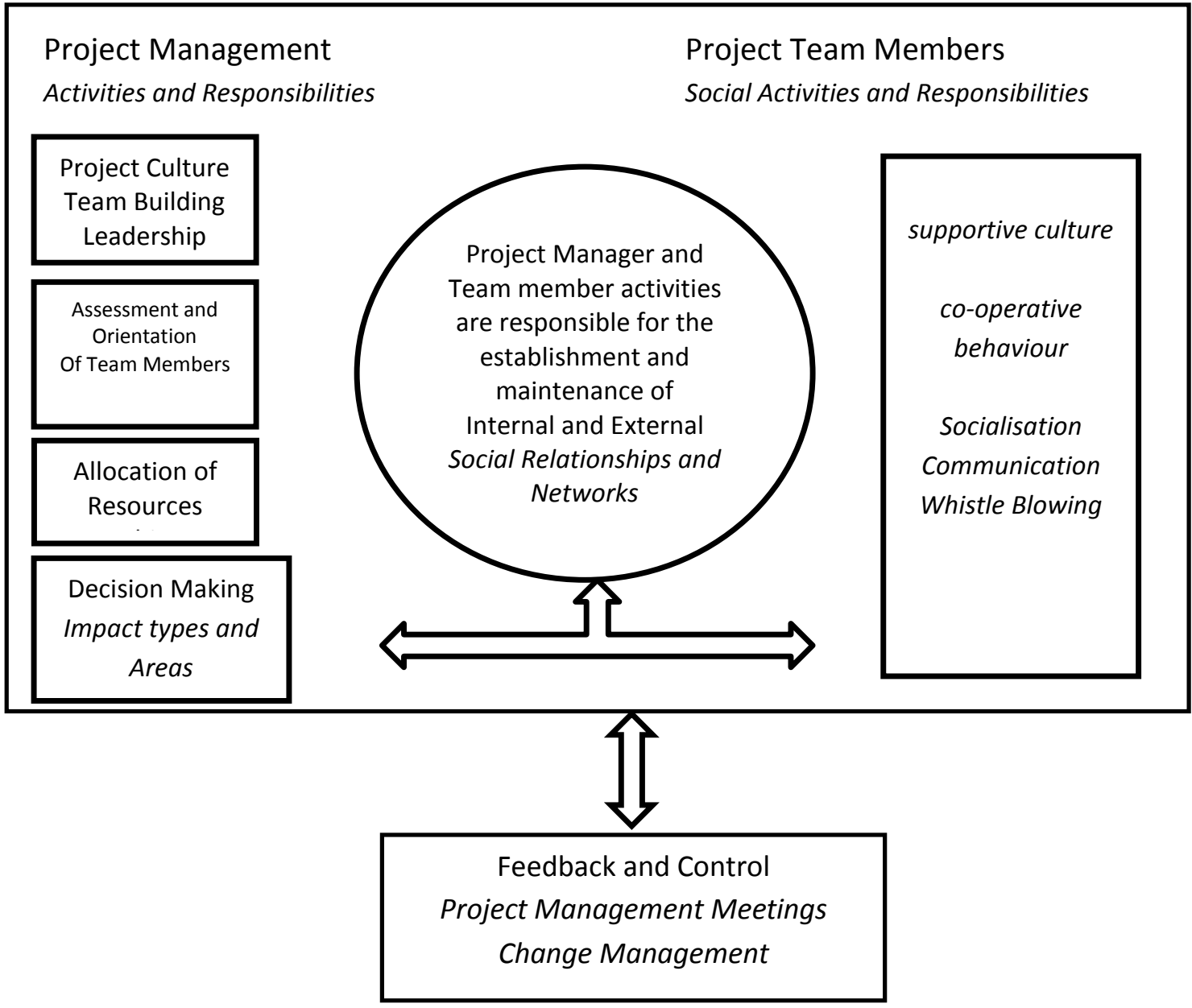

Figure 6. Conceptual framework showing the activities and responsibilities which play a role in the establishment and maintenance of social relationships and networks in the software project team environment

Source: based on Leonard (2002) and Adams et al (2010) 


\section{Conclusion and recommendations}

The results of the research illustrate that project management philosophies and methodologies alone are not enough to achieve project success and that the social relationships and networks of project team members cannot be ignored. Each project team member contributes more than just his or her knowledge and skills to the project. Social relationships and networks will develop and evolve within IT project teams and need to be harnessed to the advantage of the project to improve the likelihood of a successful outcome. This is also supported by Adams et al (2010) who state that:

As such, the project manager should assess each team member to determine his background and maturity level in social and behavioral skills. The information the project manager gains from this assessment will strengthen both the individual and the team for project success.

This research identified impact areas as well as impact types of social relationships and networks on IT projects. These impact areas and types need to be considered when project teams are established as well as monitored throughout the project life cycle. Taking cognisance of the importance of social relationships and networks within IT projects can improve the management of technology and ultimately contribute to a greater success rate of IT projects.

Furthermore, it is argued that knowledge about social relationships and networks would provide a theoretically sound supplement to the existing literature that is of value to both academics and practitioners in information systems. The nature of such relationships could help IT management to make the right decisions with regard to the composition of teams and also in terms of enhancing a satisfactory team environment. The value for practitioners lies in the guidelines as to what aspects of social relationships and networks need to be considered in establishing and managing project teams. This knowledge also contributes to existing theories of why some projects could be regarded as successes and others as failures.

It is clear that these social relationships and networks play an important role in the IT project environment. The results put an important obligation on project managers to take responsibility for these relationships and to 'allow' them for the benefit of each project and the organisation. One can argue that such relationships enhance better communication regarding issues that are normally not discussed in a formal project environment, for example, issues that need 'whistleblowing'. This brings us back to the importance of creating a project culture that should portray the following: 'Instead of shooting the messenger, managers would do well to establish ... [a] climate that encourages individuals to come forward with accurate project status information, regardless of whether the news is good or bad.' (Smith \& Keil 2003).

Therefore, social relationships between IT professionals of different teams as well as with other employees in the organisation are important to investigate at a deeper level. Furthermore, discussions between practitioners and academics should be encouraged to explore their impact on the normal operations of an IT department and ways to manage it in a professional way. 


\section{References}

Adams, S.L., Anantatmula, V. 2010, Social and behavioral influences on team process, Project Management Journal, vol. 41, no. 4, 89-98.

Adler, PS. \& Borys, B. 1996, Two types of bureaucracies: enabling and coercive, Administrative Science Quarterly 41, 61-89.

Ashworth, M.J. \& Carley, K.M. 2006, Who you know vs. what you know: the impact of social position and knowledge on team performance, The Journal of Mathematical Sociology, vol. 30, no. 1, 43-75.

Bechky, BA. 2003, Sharing meaning across occupational communities: the transformation of understanding on a production floor, Organization Science, vol. 14, no. 3, 312-330.

Collinson, S. 2000, Knowledge networks for innovation in small Scottish software firms, Entrepreneurship \& Regional Development, vol 12, no. 3, 217-244.

Faraj, S. \& Sproull, L. 2000, Coordinating expertise in software development teams, Management Science, vol. 46, no. 12, 1554-1568.

Gabarro, J.J. 1990, The development of working relationships. In Intellectual Teamwork: Social and Technological Foundations of Cooperative Work (GALEGHER J, KRAUT RE and EGIDO C, Eds), pp 79-110, Lawrence Erlbaum Associates, New Jersey.

Gargiulo, M. \& Benassi, M. 2000, Trapped in your own net? Network cohesion, structural holes and the adaptation of social capital, Organizational Science, vol. 11, no. 2, 183-196.

Hovorka, DS. \& Larsen, KR. 2006, Enabling agile adoption practices through network organizations, European Journal of Information Systems, vol. 15, 159-168.

Kadefors, A. 2004, Trust in project relationships - inside the black box, International Journal of Project Management, vol. 22, no. 3, 178-182.

Leonard, AC. 2002, A conceptual framework for managing relationships between all participants during IT service and support activities, South African Journal of Industrial Engineering, 81-96.

Liebowitz, J. 1999, A look at why information systems fail, Kybernetes, The International Journal of Systems \& Cybernetics, vol 28, no. 1, 61-67.

Meyerson, D. Weick, KE. \& Kramer, RM. 1996, Swift trust and temporary groups, In Trust in Organizations: Frontiers of Theory and Research (Kramer R.M. \& Tyler T.R., Eds). Sage, Thousand Oaks, CA.

Reich, B.H. \& Benbasit, I. 1999, Factors that influence the social dimension of alignment between business and information technology objectives. By the Society of Information Management (SIM) and the Management Information Systems Research Center (MISRC).

Sauer, C. 1993, Why Information Systems Fail: A Case Study Approach, Wiley, New York (NY).

Standing, C. 1998, Myths and the art of deception in information systems, Work Study, vol. 47 no. 1, pp.513.

Standing, C. \& Bavington, A. 1996, Implementing and using a structured information systems methodology, Accountability and Performance.,vol. 2, no. 2, 51-68.

Smith, HJ. \& Keil, M. 2003, The reluctance to report bad news on troubled software projects: a theoretical model. Information Systems Journal, vol. 13, 69-95.

Weick, K.E. \& Roberts, K.H. 1993, Collective mind in organisations: heedful interrelating on flight desks, Administrative Science Quarterly, vol. 38, no. 3, 357-382. 


\begin{abstract}
About the authors
Awie Leonard, BSc Hons (PUC), MSc (UNISA) DCom (Informatics) joined the University of Pretoria, South Africa, in 1992 as a senior lecturer, after spending several years in the private sector as a programmer/systems analyst; project manager, systems development and maintenance manager. He is now an Associate Professor in the Department of Informatics at the University of Pretoria. Apart from lecturing in a variety of information technology subjects, his research focus is in the broad field of IT service management. Since 1992 he has delivered several conference papers and published several book chapters and articles related to the field of service management in the IT field.
\end{abstract}

Email: Awie.Leonard@up.ac.za

David van Zyl MSc (Informatics) B.Com (Computer Science) has over 10 years of experience in the IT industry within the financial services and automotive industries. He gained experience across the disciplines of data analytics, software development, project management, IT Governance and IT Strategy with a focus on utilising information technology to deliver step change business value. He is currently working towards obtaining his $\mathrm{PhD}$ in Information Technology at the University of Pretoria. David grew up in the Eastern Cape and is married to Yolande and father of a daughter and son. 